\title{
Selection of Plasma Facing Materials for ITER
}

\author{
M. Ulrickson \\ Sandia National Laboratories, ${ }^{\text {A Albuquerque, NM }}$ \\ SAND $-96-1655 C$ \\ V. Barabash, S. Chiocchio, G. Federici, G. Janeschitz, and R. Matera \\ ITER Joint Worksite, Garching, Germany CONF-950905--37 \\ M. Akiba \\ Japanese Atomic Energy Research Inst., Naka, Japan \\ G. Vieider and C. Wu \\ NET Team, Garching, Germany \\ I. Mazul \\ Efremov Institute, St. Petersburg, Russia
}

\begin{abstract}
ITER will be the first tokamak having long pulse operation using deuterium-tritium fuel. The problem of designing heat removal structures for steady state in a neutron environment is a major technical goal for the ITER Engineering Design Activity (EDA). The steady state heat flux specified for divertor components is $5 \mathrm{MW} / \mathrm{m}^{2}$ for normal operation with transients to $15 \mathrm{MW} / \mathrm{m}^{2}$ for up to $10 \mathrm{~s}$. The selection of materials for plasma facing components is one of the major research activities. Three materials are being considered for the divertor; carbon fiber composites, beryllium, and tungsten. This paper discusses the relative advantages and disadvantages of these materials. The final selection of plasma facing materials for the ITER divertor will not be made until the end of the EDA.
\end{abstract}

\section{INTRODUCTION}

ITER will be the first tokamak having long pulse operation using deuterium-tritium fuel. The problem of designing heat removal structures for steady state in a neutron environment is a major technical goal for the ITER Engineering Design Activity (EDA). The steady state heat flux specified for divertor components is $5 \mathrm{MW} / \mathrm{m}^{2}$ for normal operation with transients to $15 \mathrm{MW} / \mathrm{m}^{2}$ for up to $10 \mathrm{~s}$. The neutron fluence goal for ITER is up to $3 \mathrm{MW} \mathrm{yr} / \mathrm{m}^{2}$ during the extended performance phase. The plasma facing materials must be bonded to a water cooled copper alloy substrate. The neutron fluence limits the choice of joining material because of nuclear transmutation (e.g., silver to cadmium). New brazing alloys that do not have problems with transmutations must be developed for plasma facing components. The plasma facing material must have acceptable tritium inventory and minimize safety related impacts. The technical challenge is to find materials that can withstand the heat and particle fluxes from the plasma for many thousands of cycles in the neutron environment of ITER. There is no one material that is able to simultaneously achieve all these goals. ITER is considering three materials for use as plasma facing materials: 1)beryllium, 2)tungsten, and 3)carbon fiber composites. Beryllium is the primary choice for the first wall because it is very low $\mathrm{Z}$ and erosion is low. Tungsten is favored for the highest particle flux areas because it has low erosion yield. $\mathrm{CFC}$ is preferred for the areas that may be struck by disruptions because it does not melt. There are disadvantages to using each of these materials, e.g., low melting point, high $\mathrm{Z}$, high tritium retention. $\mathrm{R} \& \mathrm{D}$ is being carried out on all three materials to determine their performance under ITER relevant conditions. Synergistic effects between the various mixtures of materials must also be studied.

\section{ITER DIVERTOR OPERATING CONDITIONS}

The ITER divertor is a single null configuration on the bottom of the machine[1]. Figure 1 shows the configuration being used for design and R\&D. There is a vertical target on both the inner and outer divertor channels. The divertor pumping is through the wings between the divertor channels. The heat loads for normal, off-normal, and disruptions are shown in Table 1.

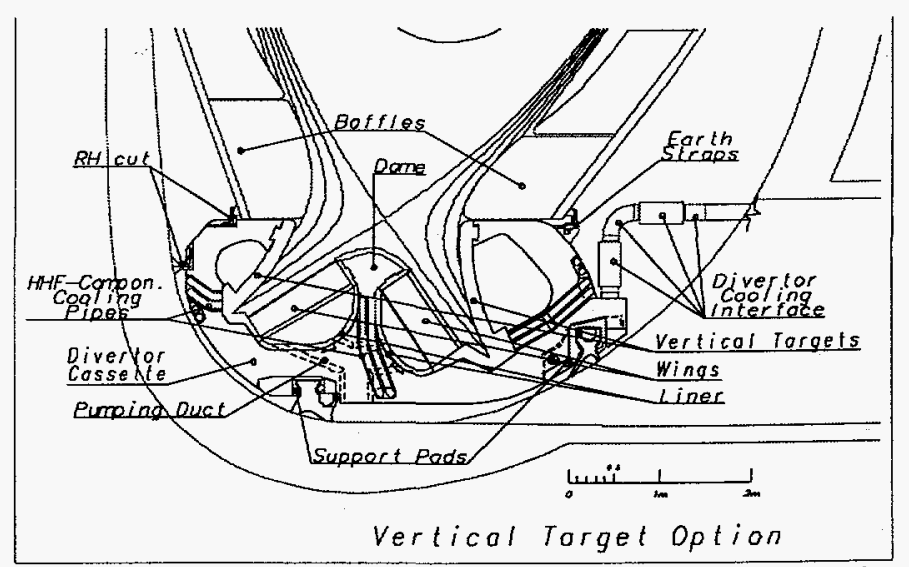

Figure 1. An elevation view of the ITER divertor showing the major components.

\footnotetext{
* Work Supported by USDoE contract No. DE-AC04-94AL85000.
} 


\section{DISCLAIMER}

Portions of this document may be illegible in electronic image products. Images are produced from the best available original document. 


\section{DISCLAIMER}

This report was prepared as an account of work sponsored by an agency of the United States Government. Neither the United States Government nor any agency thereof, nor any of their employees, makes any warranty, express or implied, or assumes any legal liability or responsibility for the accuracy, completeness, or usefulness of any information, apparatus, product, or process disclosed, or represents that its use would not infringe privately owned rights. Reference herein to any specific commercial product, process, or service by trade name, trademark, manufacturer, or otherwise does not necessarily constitute or imply its endorsement, recommendation, or favoring by the United States Government or any agency thereof. The views and opinions of authors expressed herein do not necessarily state or reflect those of the United States Government or any agency thereof. 
Table 1. Divertor heat loads.

$\begin{array}{lcc} & \begin{array}{c}\text { Heat Load } \\ \left(\mathrm{MW} / \mathrm{m}^{2}\right)\end{array} & \text { Duration }(\mathrm{sec}) \\ \text { Normal Operation } & 5 & 1000 \\ \text { Off-Normal } & 15 & 10 \\ \text { Disruptions } & 100 \mathrm{MJ} / \mathrm{m}^{2} & 0.1-10 \mathrm{msec}\end{array}$

\section{PLASMA FACING MATERIALS}

\section{Carbon}

Carbon based materials have become the standard plasma facing material is most existing tokamaks. The preferred type of carbon based material is carbon-fiber composite (CFC). A wide variety of CFC's are used in fusion devices including felt type materials, 2-D weaves, 3-D materials using high thermal conductivity fibers, and highly oriented 1-D materials using the highest thermal conductivity fiber available. Thermal conductivities of up to $800 \mathrm{~W} / \mathrm{m} / \mathrm{K}$ are available. Such large thermal conductivities enable the use of thick layers (up to $3 \mathrm{~cm}$ ) of plasma-facing material (PFM) on the heat sink. Since erosion of carbon is greater than for other materials under most conditions, the increased lifetime offered by the large thickness is required to make carbon competitive as a PFM.

Extensive conditioning is required for carbon PFM to reduce water content and control hydrogen isotope recycling. After atmospheric exposure, carbon based materials must be baked to $300-350^{\circ} \mathrm{C}$ in order to reduce the water content to levels suitable for plasma operation[2]. Some machines use $\mathrm{He}$ glow discharge conditioning between shots and extensive periods of $\mathrm{He}$ GDC overnight to reduce recycling of hydrogenic species from the walls. Other machines use low power He plasmas (TFTR), lithium pellet injection (TFTR), beryllium evaporation (JET), or boronization (TEXTOR and ASDEX) to control recycling and condition the walls when carbon based materials are used.

A major factor in the use of carbon based materials is the retention of hydrogen isotopes by eroded and redeposited material (bulk retention also exists but is much smaller). Extensive measurements of the amount of retention have been made on several tokamaks. Layers of up to $75 \mu \mathrm{m}$ have been observed as a result of only about $10,000 \mathrm{sec}$ of high power operation (about 10 ITER pulses) [3]. These layers contain up to $40 \%$ or as little as $4 \%$ hydrogen. It is not understood what causes the variations in amount of hydrogen. Extrapolation of the experimental results to ITER conditions predict between $1 \mathrm{~kg}$ and $10 \mathrm{~kg}$ of tritium trapping in codeposited layers for $10^{5} \mathrm{sec}$ of ITER operation. The codeposited layers grow with operating time without limit.

Removal of codeposited layers of carbon and hydrogen has been studied. The most effective techniques involve the use of oxygen; He-O glow discharge cleaning, ozone cleaning, or heating to $350^{\circ} \mathrm{C}$ in air or oxygen [4]. Metallic deposits in the codeposited layer may interfere with the removal process because non-volatile oxides are produced. Existing data indicate that the time required for removal is about 10 times the formation time [4]. Such a slow rate of cleaning is a problem for ITER since the duty cycle of the machine would have to be reduced and the fluence goal of $3 \mathrm{MW} / \mathrm{m}^{2}$ could not be reached. The reduction of the rate of codeposition or improvement of the cleaning rate are both the subject of intensive $\mathrm{R} \& \mathrm{D}$ during the engineering design activity.

Since carbon does not melt, disruption erosion of carbon based materials is due to sublimation. The best CFC materials show no evidence of spallation of the surface even under the extreme heat loads of a disruption. The eroded surface is smooth (no build-up due to movement of molten material) and well connected to the substrate (surface temperatures are not higher due to poorer heat transport into the bulk). For these reasons CFC's are the preferred materials for areas that may be hit by disruptions (dump targets, baffle, and dome).

Neutron irradiation of graphitic materials causes reduction of thermal conductivity [5]. Thermal conduction in graphite is primarily due to phonon conduction. The lattice damage caused by neutron bombardment causes increased phonon scattering. The impact on thermal conductivity is worst at low temperature because the displaced atoms are not mobile enough to anneal the damage. Irradiation damage can be largely removed by annealing to about $1200^{\circ} \mathrm{C}$, but this temperature is too high to be used in ITER. The graphite near the water cooled heat sink suffers the greatest loss of thermal conductivity. However, the plasma facing surface operates at about $1200^{\circ} \mathrm{C}$. Irradiation effects limit the thickness of CFC materials to $2-3 \mathrm{~cm}$.

High heat flux testing has been conducted on silver brazed CFC to copper actively cooled test articles. The results are shown in Figure 2.

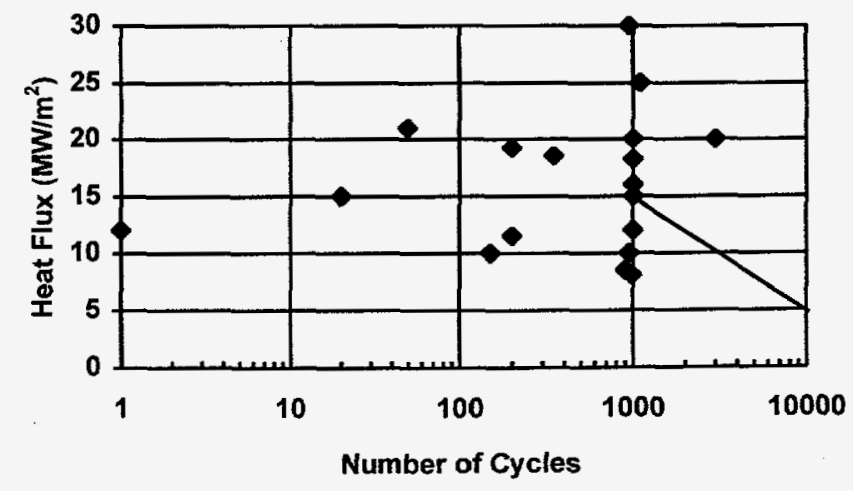

Figure 2. The results of high heat flux testing of CFC joined to copper. The ITER requirements are shown by the line.

It can be seen that samples exceeding the ITER requirements for the off-normal conditions have been produced. It is 
evident much more testing is required to assure adequate reliability under ITER conditions.

\section{Beryllium}

Beryllium was first used as a plasma facing material on the JET machine. Several beneficial effects were found. The oxygen gettering capabilities of $\mathrm{Be}$ greatly reduced the amount of cleaning required to condition graphite surfaces. Oxygen levels in JET were significantly reduced. Operation on Be limiters or divertor plates showed a complete absence of density limit disruptions and a reduction in disruption severity. There was reduced recycling and improved density control with Be compared to carbon.

Beryllium is a toxic material. Special precautions must be taken when the possibility of exposure to finely divided beryllium exists. Since the ITER divertor must be remotely handled because of neutron activation and the presence of tritium, no special restrictions result from the use of $\mathrm{Be}$.

Beryllium has a relatively low melting point $\left(1250^{\circ} \mathrm{C}\right)$. Under disruption conditions there will be extensive melting of beryllium. The stability of the melted layer determines the lifetime of a Be layer in ITER. Very few experiments on melt layer stability have been performed. Modeling of this phenomenon has just started. At present estimates of disruption lifetime have assumed no loss of melt layer or complete loss of the melt layer in order to bracket the issue. Evaporation of $\mathrm{Be}$ is considered in the disruption calculations. The predicted lifetime of a $1 \mathrm{~cm}$ thick Be layer under ITER disruption conditions is 200 disruptions assuming complete loss of the melt layer or 1000 disruptions assuming no loss of the melt layer [6].

Irradiation of Be produces helium in the metal because of the $(n, 2 n)$ reaction. Another branch of the neutron reaction produces tritium in beryllium. Helium is insoluble in $\mathrm{Be}$. Helium bubble formation eventually causes embrittlement and swelling of $\mathrm{Be}$. Initial estimates of erosion of beryllium indicate that $\mathrm{Be}$ components will have to be replaced before swelling becomes an issue. Initial results from irradiation to 1 displacement per atom (dpa) show no loss of thermal conductivity. Evaluations of embrittlement are in progress.

High heat flux testing of beryllium has been conducted. Some samples have survived for up to 9600 cycles at 5 $\mathrm{MW} / \mathrm{m}^{2}$, but reliability of available joining technology is not adequate because only $\sim 25 \%$ of the samples were of high quality (see Figure 3). The tests did reveal no fatigue cracking of $\mathrm{Be}$ at $5 \mathrm{MW} / \mathrm{m}^{2}$. Fatigue testing at higher heat flux revealed large variations in the thermal fatigue resistance of various grades of Be. The two best grades are S65-C (US) and DshG200 (Russia). The R\&D efforts are focusing on these two grades. Considerably more thermal testing is required to prove the reliability of $\mathrm{Be}$ under the steady state heating conditions in ITER.

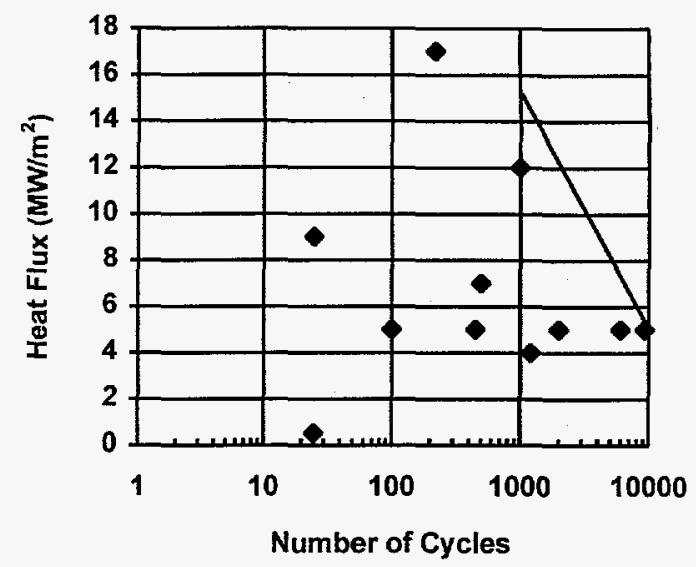

Figure 3. Results of high heat flux testing of $\mathrm{Be} / \mathrm{Cu}$ joints. The line represents the ITER requirements.

Plasma spray repair of eroded or disruption damaged surfaces inside ITER is one method to increase the lifetime of plasma facing components. Plasma spray of beryllium has improved greatly during the EDA. Initially, the thermal conductivity of plasma sprayed beryllium was about $60 \%$ of theoretical at about $75 \%$ density. The latest material has $98 \%$ of theoretical thermal conductivity at $98 \%$ density [7]. High heat flux testing of the best material has not started. Surfaces of beryllium damaged in the ISX-B tokamak have been cleaned using the transferred arc method where the plasma gun is biased relative to the substrate being coated causing an arc to be drawn to the gun. Carbon, tungsten, and oxygen have all been successfully cleaned from the surface using transferred arc cleaning. About $2 \mathrm{~mm}$ of new $\mathrm{Be}$ was deposited on damaged and undamaged surfaces of the ISX-B tiles. The deposits were tested at $5 \mathrm{MW} / \mathrm{m}^{2}$. After about 800 cycles cracks developed in the coating, but the cracks were perpendicular to the surface. Further tests are planned, but the results indicate in-situ repair of eroded surfaces is possible in ITER.

An alternative method for recoating surfaces is using thermal evaporation of $\mathrm{Be}$. Samples of $\mathrm{Be}$ coated with thermally evaporated beryllium have been subjected to high heat flux testing. The samples showed rapid failure due to poor adhesion of the coating to the substrate. The native surface oxide layer is the most likely reason for the poor bonding. A cleaning technique like transferred arc must be developed if thermal evaporation is to be successful.

\section{Tungsten}

Tungsten was used as a limiter material in the PLT device (among others) in the late 1970's. Poor plasma performance was observed due to plasma contamination of the high atomic 
number ( $\mathrm{Z}$ ) material. Molybdenum was used on the JT-60 device, but was later changed to graphite because of the success of graphite lined machines. Recently Alcator C-Mod has used molybdenum as a limiter and wall material. C-Mod has not seen any Mo contamination problems when they operate at high density. When lower density is used, they do observe Mo eroded from the first wall (not the divertor). These recent results indicate that high $Z$ elements may be used in a tokamak with a divertor. Tungsten divertor plates are planned to be used in ASDEX soon.

Since tungsten is a heavy atom, the threshold energy for sputtering by hydrogen is high. If the plasma temperature at the divertor plate is below about $75 \mathrm{eV}$, the erosion rate for tungsten is zero. Modeling of the erosion rate under ITER divertor conditions has shown that the predicted lifetime of tungsten is about 100 times that of carbon or beryllium [8]. This is the main advantage of tungsten.

Because tungsten has high $Z$, it can cause a very large power loss in the plasma. The allowed concentration of tungsten in the plasma is about $0.001 \%$. For this reason, it is unlikely W will be considered for application to the first wall of ITER. The use will probably be limited to potentially high erosion areas in the divertor (vertical target, dump target, and wings).

Disruption heat loads will cause melting of tungsten. Modeling of the energy deposition on tungsten during a disruption has shown that the melt layer thickness is about twice that on $\mathrm{Be}[6]$. The issues regarding the stability of melt layers on $\mathrm{W}$ are the same as those for $\mathrm{Be}$. The predicted disruption lifetime for $\mathrm{W}$ is 500 disruptions assuming complete loss of the melt layer and 1500 disruptions assuming no loss of the melt layer.

Tungsten has been used in rocket nozzle applications. In that use the tungsten is cooled by evaporation of infiltrated copper or silver (transpiration cooling) [9]. We are investigating the use of lithium or magnesium infiltrated $W$ for areas that may be hit by disruptions. These low $Z$ materials are preferred because the evaporated material may be transported to an area where it can enter the plasma. The cooling effect of the infiltrant can reduce the melting of the tungsten and increase the disruption lifetime.

Plasma spray of tungsten has yielded coatings having about $90 \%$ density and $>80 \%$ thermal conductivity. Such coatings have not yet been tested under ITER conditions. Graded layers of copper and tungsten have also been produced by plasma spray. Such layers can reduce the thermal stresses at the interface between $\mathrm{Cu}$ and $\mathrm{W}$. Chemical vapor deposition (CVD) of W could also be used to repair eroded W surfaces. CVD coatings are being prepared for high heat flux testing.

High heat flux tests have been conducted on tungsten joined to copper. The results are shown in Figure 4. Some of the samples have come close to meeting ITER requirements. More testing is required to assure reliability of $\mathrm{W} / \mathrm{Cu}$ joints.

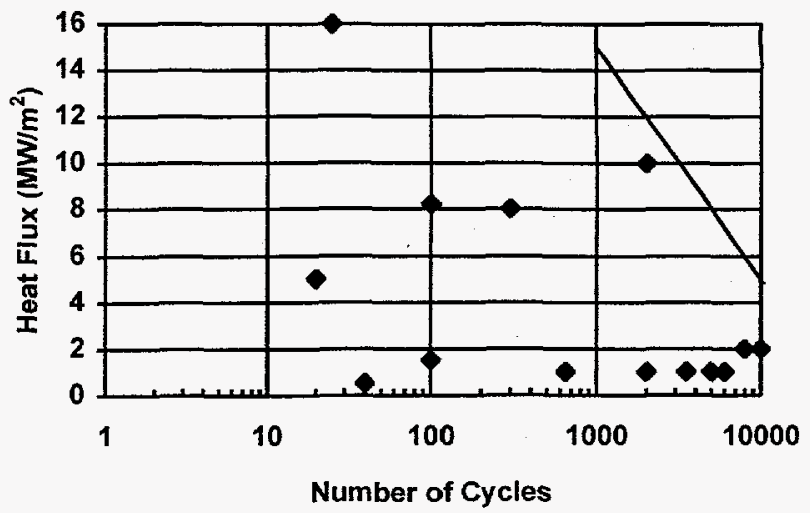

Figure 4. Results of high heat flux testing of $\mathrm{W}$ bonded to $\mathrm{Cu}$. The line represents the ITER requirements.

\section{HEAT SINK MATERIAL ISSUES}

Several copper alloys are being considered for use at the heat sink material in the ITER divertor. Two of the alloys are precipitation strengthened alloys; copper-chromiumzirconium (Elbradur-Gß) and copper-beryllium-nickel (Hycon-3®). The third alloy is aluminum oxide dispersion strengthened copper (Glidcop(B). These are all high strength copper alloys. Electromagnetic loads during disnuptions and the operating pressure of $4 \mathrm{MPa}$ at $150^{\circ} \mathrm{C}$ determine the need for high strength. Irradiation of copper alloys has shown that these materials are strengthened by irradiation but also embrittled if the irradiation is performed at less than about $100^{\circ} \mathrm{C}$ [10]. There is some evidence that heating the irradiated material to about $350^{\circ} \mathrm{C}$ may anneal the damage and restore some of the ductility. This is a second reason for requiring $350^{\circ} \mathrm{C}$ bakeout capability on ITER (see the carbon section above). This implies that the braze alloys selected for joining the plasma facing material to the copper must have a liquidus temperature above $350^{\circ} \mathrm{C}$. On the other hand very high braze temperatures (greater than about $600-700^{\circ} \mathrm{C}$ ) can cause overaging of the precipitation hardened alloys $(\mathrm{CuCrZr}$ is the most susceptible). The heat sink material has a strong influence on the selection of the joining material between the plasma facing material and the heat sink.

\section{JOINING OF PLASMA FACING MATERIAL TO THE HEAT SINK}

The most common method used to join plasma facing materials to cooled substrates in existing machines involves the use of silver containing braze alloys. Neutron irradiation of silver causes severe activation of silver and conversion of silver to cadmium. Slow neutron capture by $\mathrm{Ag}^{109}$ creates $\mathrm{Ag}^{110 \mathrm{~m}}$ having a half-life of 249 days (also $\mathrm{Ag}^{107}$ creates $\mathrm{Ag}^{108 \mathrm{~m}}$ with a half life of $\sim 5 \mathrm{yr}$ ). Both of the meta-stable states decay to $\mathrm{Cd}$. A short term problem is caused by the 
decay of the meta-stable (contact dose), and a long term problem is the conversion to cadmium lowering the melting point of the braze $\left(\sim 800^{\circ} \mathrm{C}\right.$ to $\left.\sim 550^{\circ} \mathrm{C}\right)$. Cadmium is a high vapor pressure toxic material. High contact dose will have a severe impact on remote handling vision equipment and lengthen the time required to maintain the divertor. The cadmium is a disposal issue and may lead to plasma contamination due to evaporation (from disruptions perhaps).

Development of new braze alloys and techniques is nearing the end of the first phase. For carbon and tungsten, the work centers on infiltration of copper into slightly porous CFC or W followed by direct bonding of copper to copper, e.g. by diffusion bonding. The use of graded layers having varying compositions of $\mathrm{W}$ and $\mathrm{Cu}$ are under development. Such layers can help accommodate the mismatch in expansion coefficient between $\mathrm{W}$ and $\mathrm{Cu}$. Beryllium forms a wide variety of intermetallics with most materials. Aluminum and germanium are two of the few materials not forming such intermetallics. Since $60 / 40$ beryllium-aluminum is a nearly perfect match to the expansion coefficient of copper, we have focused our efforts on using Al containing materials for joining $\mathrm{Be}$ to $\mathrm{Cu}$. Diffusion barriers must be used to prevent formation of $\mathrm{Al} / \mathrm{Cu}$ intermetallics. Samples prepared using explosion bonding, diffusion bonding, and brazing using Al$\mathrm{Si}$ and $\mathrm{Al}-\mathrm{Ge}$ alloys are all being prepared for high heat flux testing. Testing of these new bonded structures is being reported at this conference.

All three of the plasma facing materials being considered for ITER have thermal expansion coefficients that are considerably different from copper. One way to reduce the stress induced by the mismatch in expansion is to use a soft compliant layer between the copper and the PFM. Such a soft layer could also prevent propagation of cracks from the PFM to the copper heat sink. Since cracks in the $\mathrm{Cu}$ could lead to loss of coolant, compliant layers could improve the safety of the entire system. Two different compliant layers are being investigated. The $\mathrm{Cu}-\mathrm{Pb}$ binary system has a very large difference between solidus and liquidus (about $400^{\circ} \mathrm{C}$ ). This system is being investigated for use in $\mathrm{W} / \mathrm{Cu}$ and $\mathrm{CFC} / \mathrm{Cu}$ joints. Operating with the $\mathrm{Cu} / \mathrm{Pb}$ between the solidus and liquidus yields a thixotropic liquid having a large viscosity making it possible to remove the PFM from the heat sink. Addition of Ti to the $\mathrm{Cu} / \mathrm{Pb}$ alloy is necessary to improve the wetting of $\mathrm{W}$ and CFC. An alternate system consisting of a $\mathrm{Ni}$ felt metal filled with CuSn or CuGe is also being investigated. The felt metal acts as a carrier to retain the low melting soft solder. High heat flux testing of joints made using both techniques is planned.

\section{CONCLUSIONS}

Each of the materials being considered for plasma facing components has a particular location or operating regime where it has an advantage over the other materials. It is unlikely that any one of the materials will prove to be the only material chosen for ITER. Since each of the candidates also has disadvantages or limitations, it is important to continue the research and development necessary to qualify all three materials. The joining development needed to bond the materials to copper heat sinks with reliability and adequate cyclic fatigue life is generic to all potential divertor physics scenarios. Neutron irradiation of the materials and joints is one of the key elements of the R\&D program. Development of compliant layers can significantly reduce the stresses at the interface between the plasma facing material and the heat sink. This would improve the reliability and lifetime of the component. Improved data on erosion rates of the base materials and combinations of the three materials would improve the predictions of the lifetime of the components. Stability of the melt layers on metallic materials would also improve the lifetime predictions. Tritium retention and tritium compatibility of the three candidate materials and the joining materials are key issues. The modular divertor design chosen for ITER allows for exchange of plasma facing components rapidly. This flexibility also allows any of the three materials to be chosen for any component if the basic supporting development is completed during the EDA. The final decision on the material(s) to be used need not be made until after the EDA when actual construction must begin. Results from initial operation of the device can be used to alter the initial decision. The supporting data will prove useful under this circumstance because it will allow new designs to be based on the data accumulated during the EDA.

\section{REFERENCES}

[1] ITER Design Description Document Section 1.7

[2] ITER Physics Design Description Document

[3] H.F.Dylla and K.L. Wilson, ed., Tritium Retention in TFTR, SAND88-8212, Oct. 1988.

[4] W. Hsu, Glow-discharge Removal of Codeposited Carbon Films in Graphite Lined Tokamak Reactors, J.Vac.Sci.Technol. A7, 1047-1051, 1989.

[5] L. Snead, presented at the International Conference on Fusion Reactor Materials, Obninsk, Russia, Sept 1995.

[6] A. Hassanein, presented at the International Conference on Fusion Reactor Materials, Obninsk, Russia, Sept 1995.

[7] R. Castro, presented at the Beryllium Workshop, Jackson Hole, WY, Sept 1995.

[8] J. Brooks, unpublished.

[9] J.W. Davis, presented at the International Conference on Fusion Reactor Materials, Obninsk, Russia, Sept 1995.

[10] S. Zinkle, presented at the International Conference on Fusion Reactor Materials, Obninsk, Russia, Sept 1995. 